\title{
Discussion
}

\section{Coping with the Future: \\ The Brexit Kodak Moment}

\section{Richard Ennals}

\begin{abstract}
It is all too easy for politicians and other decision makers to ignore or fail to take account of research which would complicate their decision-making processes. In this article we take the case study of the UK and departure from the European Union (known as "Brexit"). A Referendum in June 2016 voted to Leave. The case was discussed in a keynote talk at the "Coping with the Future" conference at the University of Agder in October 2018. Crisis and chaos continue in October 2019.
\end{abstract}

Keywords: Brexit, Kodak Moment, temporal logic 


\section{A Writing Project}

In early 2017 there was a writing workshop in Copenhagen, organised by the University of Agder, which brought together researchers and $\mathrm{PhD}$ students, largely from Norway, who shared a need to write and publish. As is my habit, I was taking detailed notes of the series of presentations. In my room at the end of the day I identified an emerging theme: "Coping with the Future". I also identified a new concept, which was introduced by Halvor Holtskog: "Kodak Moments": disruptive and transformative events.

The book "Coping with the Future: Rethinking Assumptions for Society, Business and Work", edited by Johnsen, Holtskog and Ennals, published in April 2018 was the outcome of an intensive collaborative process. Each chapter was co-authored and repeatedly edited, going through many stages of a collective creative process. The book does not promote a Nordic or Norwegian Model: it exemplifies it. I have no doubt that each of our team of contributors would highlight different aspects of the project and the book, starting from their own specialist perspectives. This article is a personal view.

\section{Action Research and Kodak Moments}

I have been an Action Researcher for 50 years. I chose to add a focus on particular "Kodak Moments", going beyond the narrow focus of individual companies. Readers will see discussion of the Brexit process in the UK; and of the election of President Donald Trump in the USA. Both events were unexpected, disruptive and transformation, with enormous continuing impacts. They reinforce the view that the future is uncertain and unpredictable. This presents particular challenges for social science, which are explored in the book.

I am not content to observe. I am engaged, as a senior citizen of a society undergoing change at all levels: local, original, national and international.

In the early summer of 2017, as our book was taking shape, I was approached by Allan Larsson: former Swedish Minister of Finance, Director-General for Employment and Social Affairs in the European Commission, and recently a personal adviser to the Swedish Prime Minister, the President of the European Commission, and the Director-General of the International Labour Organisation.

Larsson wanted to know what was going on in the UK, with regard to Brexit. I explained that I have no power in UK politics. I have worked with Larsson on a number of occasions since 1998, trying to understand and improve the world in which we are living through, in difficult times. See Concepts and Transformation 3.1. 1998, and the European Journal of Workplace Innovation 3.12017.

\section{Brexit for Beginners}

On 7th October 2017 I submitted an article "Brexit for Beginners", in the "Curmudgeon Corner" section of $A I \&$ Society, drawing on the literature of belief systems in Artificial Intelligence. It was published online a few days later. I introduced the key dramatis personae, and the basic plot of an interactive theatre piece, "The Young Gentlemen of Etona". The focus was on key individuals who met as students at Oxford. Several of them, including David Cameron and Boris Johnson, had previously been pupils at Eton College. They were long-term rivals for political power in the UK. Their desire for political power was stronger than their adherence to particular political principles.

In research terms, I have been interested in whether the conjectures in this article, from October 2017, have subsequently been refuted. In November 2018 the article was published in AI \& Society 33.42018. 


\section{The Brexit Negotiations}

There is an additional context which we must consider. Events in the real world have continued to develop. As I spoke on $9_{\text {th }}$ October 2018, I needed to consider how to cope with a future which was due to be announced on 10th October, when the Chief EU Negotiator on Brexit, Michel Barnier, reported on the progress of negotiations. There was a scheduled European Council meeting on $17_{\text {th }}-18$ th October, and potentially there could be a special summit on $17_{\text {th }}-18_{\text {th }}$ November 2018. The UK was due to leave the EU on 29th March 2019. There were then two delays: the current scheduled departure date is $31_{\text {st }}$ October 2019.

Each day, we still cannot predict with any certainty what will happen tomorrow. If you listen to my keynote talk, or read the text which I used, you can compare it with the continuing public picture.

It is not my task in this article to argue for a particular position on Brexit. My action research has included engagement with conversations and dialogues across many political parties, countries and disciplines. My key findings concern the logical, legal and cultural context of the Brexit debate.

As I wrote the keynote talk, there was an effective news blackout on what is going on behind closed doors. The negotiators for the UK and the EU entered the "tunnel", in order to achieve a final draft agreement. This happened again with the new Prime Minister Boris Johnson.

I have been active in Facebook debates which have been hosted by Allan Larsson. On 7th October 2018, my online discussion reached the point where my interlocutor confessed that he could not follow my argument. This was not due to a lack of knowledge of the law and politics. It was a question of being unable to follow the logic. On Monday 8th October I added a wealth of new arguments, taking account of temporal logic.

\section{Gödel and Howorth}

My starting point was a philosophical problem which was raised by considering the work of both Kurt Gödel (1962) and Jolyon Howorth (2018), who set out clear guidance on what could be handled by logic and negotiations. In 1931, Gödel, in his "Incompleteness Theorem", first argued that symbolic systems, at a given level of abstraction, could not be both complete and consistent. That has constrained our understanding of what is possible in the key technical field of logic and computer science.

Jolyon Howorth is Emeritus Jean Monnet Professor of European Law at Bath University, with visiting professorial posts at Yale and Harvard. In an LSE blog published on 25th September 2018, Howorth argued that, given the stated "red lines" of the various parties to the Brexit negotiations, and in particular the UK government, there was no possibility of a successfully negotiated deal. He recommended that the Prime Minister Theresa May should acknowledge this, and seek to revoke Article 50 of the Lisbon Treaty.

For Brexit, this increased the focus on finding solutions to the thorny problems of the Irish border and customs arrangements. Again, in this article I do not need to adopt particular positions. As I write today, UK Prime Minister Boris Johnson is trying to secure Parliamentary approval for his own proposed solution to the continuing problem. Crucially, he changed the "red lines" regarding Northern Ireland.

With the help of logicians and lawyers, I have been exploring how complex problems can be represented in logic. This builds on work at Imperial College in 1985, where I was research manager. The Imperial College team, led by Robert Kowalski, represented the 1981 British Nationality Act in predicate logic, and interrogated it on the computer, as a logic program. There was a presentation at the Royal Society. There were radical but largely undiscussed implications for practical democracy. 


\section{Temporal Logic}

In this article I focus on the additional technical areas of temporal logic and non-monotonic reasoning.

My Facebook interlocutor argued, with impressive authority, that once there was agreement on the terms of withdrawal, with a Withdrawal Agreement, then Brexit would take place, and that the process would be irreversible.

I argued that the Leave majority in the 2016 referendum was respected, when the UK went ahead with the Article 50 process. However, although there was agreement on a mood of opposition to UK membership of the EU, there had as yet been no agreement on an alternative destination. The two stages of "divorce", and developing a new trade relationship, were to be handled separately.

\section{Are we nearly there yet? Unfortunately, we do not know, as we have not yet set a destination in our "Policy Sat Nav".}

What do we want? We don't know. When do we want it? Now.

\section{No Deal or No Brexit}

Theresa May repeatedly warned that if there was no rapid agreement on defining the chosen Brexit settlement, then there would be a risk of "No Brexit".

What does that mean? It should not necessarily mean "No Deal", with the catastrophic economic and social consequences which would be likely. The UK and the EU could reach some pragmatic understanding. Donald Tusk, President of the European Council, has expressed this view.

The situation would not be an example of that form of breakdown, resulting in No Deal. The issue would be the continued absence of a UK position, and the lack of parliamentary support for any given Brexit model, such as "Norway" and "Canada +++". On that basis, there was effectively no possibility of a Brexit deal, as there is no public substantive UK government proposal which meets EU "red lines". This continues to be the situation in October 2019.

In principle, therefore, I suggested that the correct next step, in constitutional terms, would be for the UK to revoke Article 50 of the Lisbon Treaty. This echoed the view expressed by Jolyon Howorth, in his blog published by LSE on 25th September 2018.

My Facebook interlocutor argued that once withdrawal is agreed, then it is too late to revoke Article 50 , which would also require unanimous approval by the other $27 \mathrm{EU}$ member states. However, before the Withdrawal Agreement has been reached, revocation of Article 50 is possible. Once confirmed by the EU 27 member countries, this would lead to the outcome of "No Brexit". The UK Parliament has since rejected the Withdrawal Agreement three times. This week it is to be asked to vote again.

\section{Non-monotonic reasoning}

What does this mean for the frequently stated principle that "nothing is agreed until everything is agreed."? We may begin to realise that it makes little sense. It does not capture the nature of negotiations, which are incremental and dynamic, with developing areas of consensus and trust.

We are being invited to engage in non-monotonic reasoning, which involves analysing a data base of propositions which is constantly changing, based on moves in the negotiation process. There can be advances and retreats, progress and setbacks.

In 1980, with a pilot class of 9-year old pupils, I developed and published a murder mystery database (Ennals 1983). As more evidence was collected, the database was updated. Pupils sought to plant evidence to incriminate particular suspects. Susie had been killed with a "blunt instrument". Our pupil detectives listed a number of possible weapons, including a football boot, a cricket bat, and a wooden 
leg. They reasoned with a changing database. Purists such as Professors Michael Griffiths and Pat Hayes deplored this non-monotonic reasoning. Meanwhile, the example spread across the world, for example as "Sherlock Holmes", but with distinctive and familiar items of evidence.

There was a related issue, explored by Keith Clark (1978) at Imperial College: "negation as failure". The answer "NO" to a query to a database should be understood as "Not proven to be YES".

\section{Temporal Logic: Goodman's Paradox}

There is a classic logical paradox which offers insight into temporal logic. Nelson Goodman (1955), in "Goodman's Paradox", used the example of "Grue". This means "Green before noon and Blue after noon". The meaning of "Grue" changes with the time of day. This provides a powerful lens with which to scrutinise major policy changes, such as the UK Government's Universal Credit system.

There are clearly issues around the temporal dimension. It does not seem obvious that politicians and negotiators have grasped the complexities of temporal logic.

What is the consequence of this gap in understanding? It appeared that if the gap was not filled before Michel Barnier made his report on 10th October 2018 in Brussels, then it might simply be too late. There is a stated sequence of stages in the Brexit process, but without reversibility, or understanding of the issues concerned. Boris Johnson's team appear to have understood this, as the new deal implicitly required the Withdrawal Agreement to be renegotiated, to take account of the changed "red lines".

The apparent failure to grasp the temporal dimension of legislation and negotiation casts a giant shadow across the workings of our countries, and of international relations.

\section{Channel Tunnel}

I should add that the logics of law in the UK and the EU have distinct histories. Linking them in treaties is like building the Channel Tunnel, as was memorably studied by the Tavistock Institute (Pomares 2018). The cultures of working life on the two sides of the Channel were very different.

\section{Cliff Edge}

The UK has sleepwalked to the cliff edge of disaster. Disaster can still be averted, but, literally, it still requires "action this day". A few targeted conversations could halt the runaway train in time. We need words and actions.

Can we cope with the future? We may soon find out. 


\section{References}

Ennals R. Beginning micro-PROLOG. Chichester, Ellis Horwood, 1983.

Ennals R. "Partnership for a new organisation of work and Europe as a development coalition: An interview with Allan Larsson, Director-General of DG-V, European Commission." Concepts and Transformation 3.11998 1-10.

Ennals R. "Brexit for Beginners: The Young Gentlemen of Etona". AI \& Society: Knowledge, Culture and Communication, 33.42018.

Clark K. "Negation as Failure". In Gallaire H. et al (eds.) Logic and Data Base. New York, Plenum 1978.

Goodman N. "Goodman's Paradox" in Fact, Fiction and Forecast. Oxford. OUP 1955.

Gödel K. “The Incompleteness Theorem”. In Meltzer B. and Braithwaite R. On Formally Undecidable Propositions of Principia Mathematica and Related Systems. New York, Dover 1962

Howorth J. "Brexit has become unnegotiable." LSE Blog. 25th September 2018.

Johnsen H.C.G., Holtskog H. and Ennals R. (eds.) Coping with the Future: Rethinking Assumptions for Society, Business and Work. London, Routledge 2019.

Larsson A. "How to understand the times we are living through". European Journal of Workplace Innovation. 3.1. 2017.

Pomares E. Personal Communication. October 2018.

Sergot M., Sadri F., Kowalski R., Kriwaczek F., Hammond P. and Cory T. “The British Nationality Act as a Logic Program." Communications of the ACM.29.5 1986 